\title{
PENGARUH INTENSITAS CAHAYA TERHADAP PEMANGSAAN LARVA IKAN CLOWN(Amphiprion ocellaris) PADA AWAL PEMELIHARAAN
}

\author{
Ketut Maha Setiawati*), Philip Teguh Imanto*), dan Daniar Kusumawati*)
}

\begin{abstract}
ABSTRAK
Penelitian pemangsaan larva ikan clown (Amphiprion ocellaris) pada awal pemeliharaan dan umur sepuluh hari dilakukan menggunakan tangki serat kaca (fiberglass) volume 200 L. Pakan zooplankton rotifera disediakan sejak telur menetas dengan kepadatan 5 ind./mL. Mulai D-8 zooplankton nauplii Artemia ditambahkan dengan kepadatan 1.700 ind./tangki. Pengambilan sampel dilakukan pada umur 1 hari dan sepuluh hari, masing-masing 10 ekor larva/sampling dengan interval waktu 3 jam. Larva diukur kemudian dibedah dan dianalisis jumlah pemangsaaannya dengan bantuan stereoscopic microscope. Hasil analisis menunjukkan peranan intensitas cahaya dalam aktivitas pemangsaannya sebesar 5 individu rotifera dengan intensitas cahaya 70 lux pada pagi hari, sedang pemangsaan tertinggi terjadi pada pukul 13.00-16.00 dengan pemangsaan 57 individu rotifera pada saat intensitas cahaya menurun. Spektrum warna cahaya diduga lebih berperanan pada kemampuan maksimal memangsa dari larva ikan laut.
\end{abstract}

ABSTRACT: The effect of light intensity on feeding of clown fish Amphiprion ocellaris larvae in its early rearing. By: Ketut Maha Setiawati, Philip Teguh Imanto, and Daniar Kusumawati

Observation on feeding activity of clown fish (A. ocellaris) larvae have been conducted in 200 L. fiberglass tanks. Zooplankton rotifers were used as initial feed at a rate of 5 ind./mL. After eight days culture, nauplii Artemia were added at rate of 1,700 ind./ tank. Sampling was done on D-1 and D-10 at 10 individuals even sampling at three hours interval. The larvae were measured under a stereoscopic microscope, examining the digestion apparatus to count number of rotifers and nauplii Artemia as well. The result showed that the role of light intensity in feeding: 5 individual rotifer at 70 lux in early morning for D-1 larvae. The highest feeding occurred at 13.00-16.00 in the after noon at 57 individual rotifer when light intensity decreased. Color spectrum of light were predicted having more roles related to the maximum feeding rate of clown fish larvae.

\section{KEYWORDS: larvae, clown fish, feeding, light intensity, rotifer, Artemia}

\section{PENDAHULUAN}

Ikan clown (Amphiprion ocellaris) merupakan salah satu jenis ikan hias laut yang bernilai ekonomis tinggi. Sebagian besar hasil tangkapan ikan hias laut Indonesia hanya untuk kebutuhan ekspor. Harga ikan clown yang berukuran kecil US\$ 0,45 sedangkan yang berukuran medium mencapai US $\$ 0,65$ (Anonim, 2006).
Penyebaran ikan clown hanya terdapat di perairan tropis di antaranya adalah di bagian Selatan, Tengah, Barat Samudera Pasifik, Samudera Hindia, Laut Merah, Peninsula Sinai, dan Pantai Afrika Timur sampai French Polynesia. Penyebarannya juga meliputi utara Jepang sampai Australia (Kuiter, 1996; Allen, 2000; Wilkerson, 2003). Habitatnya sangat bervariasi dari karang yang terlindung didalam teluk hingga perairan dalam tepi karang laguna

\footnotetext{
*) Peneliti pada Balai Besar Riset Perikanan Budidaya Laut, Gondol
} 
maupun di dalam karang dasar (reef slope) (Kuiter, 1996). Ikan clown temasuk salah satu jenis ikan hias laut dari famili Pomacentridae yang banyak terdapat di Indonesia. Ikan hias laut (clown fish) merupakan ikan hias yang hidup diperairan terumbu karang, banyak tersebar di Teluk Jakarta, Lampung, Aceh, Bali, Madura, Sulawesi, Maluku, dan Irian Jaya; panjang tubuhnya dapat mencapai $15 \mathrm{~cm}$ dengan 3 belang putih di bagian kepala, badan dan pangkal ekor (Poernomo et al., 2003). Ada 2 genera ikan clown yaitu Amphiprion dan Premnas. Genus Amphiprion ada 27 spesies, dan genus Premnas hanya ada 1 spesies.

Pembenihan ikan clown sudah dilakukan sejak tahun 2005 di Balai Besar Riset Perikanan Budidaya Laut, Gondol bekerja sama dengan CV Dinar Denpasar, mulai dari domestikasi induk, pematangan, pemijahan, penanganan telur serta pemeliharaan larva dan benih. Penelitian mengenai pola pemangsaan pada stadia larva ikan clown belum banyak dilakukan. Informasi pola pemangsaan merupakan salah satu data dasar yang penting untuk diketahui sehingga dapat dipergunakan pada manajemen pemeliharaan larva seperti penyediaan pakan dan pengaturan intensitas cahaya. Pada ikan kerapu lumpur, Epinephelus coioides dan kakap merah, Lutjanus argentimaculatus; dan $L$. sebae pola pemangsaannya sangat tergantung pada kondisi tingkat pencahayaan (Imanto et al., 2001; Melianawati et al., 2006a).

Tujuan dari penelitian ini adalah untuk mengetahui pola pemangsaan larva ikan clown pada awal pemeliharaan sampai umur 10 hari, serta hubungannya dengan intensitas cahaya terhadap pola makan larva ikan clown.

\section{BAHAN DAN METODE}

Telur ikan clown diperoleh dari hasil pemijahan induk ikan clown alam dan dipelihara di akuarium. Setelah memijah telur akan menempel pada substrat (semen, sudut akuarium, maupun pada pipa PVC), dan telur tersebut akan dijaga oleh sepasang induknya selama enam hari, kemudian pada hari ke- 6 telur-telur ikan clown dipisahkan dari substratnya dan ditempatkan pada tangki pemeliharaan larva. Wadah pemeliharaan larva menggunakan tangki serat kaca (fiberglass) volume $200 \mathrm{~L}$. Kepadatan telur/tangki berkisar 100-200 butir. Plankton Nannochloropsis ditambahkan pada tangki pemeliharaan larva setelah telur menetas. Pakan untuk larva berupa rotifera yang diberikan sejak telur menetas dengan sediaan dua kali dalam sehari untuk menjaga kepadatan rotifera dalam bak pemeliharaan sebanyak 5 ind./mL. Sejak D-8 zooplankton nauplii Artemia ditambahkan dengan kepadatan 1.700 ind./tangki. Pemberian Artemia juga dilakukan dua kali sehari yaitu pada pukul 10.00 dan 15.30 WITA.

Pengamatan tingkat pemangsaan dilakukan pada saat larva berumur sehari dan 10 hari. Pengambilan sampel sebanyak 10 ekor dilakukan mulai pukul 07.00 dan 10.00 interval waktu selama 3 jam hingga pukul 04.00 keesokan harinya. Setiap pengambilan sampel dilakukan pengukuran intensitas cahaya pada wadah pemeliharaan dengan Illuminance meter pada kedalaman $20 \mathrm{~cm}$.

Setiap sampel dilakukan pengukuran panjang total dan panjang standar kemudian dilakukan pembedahan untuk menghitung jumlah rotifer maupun Artemia yang terdapat dalam saluran pencernaannya. Semua kegiatan dilakukan di bawah mikroskop stereo (stereoscopic microscope) yang dilengkapi dengan ocular micrometer.

\section{HASIL DAN BAHASAN}

Hasil penelitian diuraikan dalam dua bagian yang meliputi penampilan fisik dari larva yang dipelihara maupun pada aspek pemeliharaan larva dengan tekanan pada aktivitas pemangsaannya.

\section{Pemeliharaan Larva}

Gambar 1 menunjukkan bahwa pada saat pemangsaan awal, kemampuan larva sangat erat kaitannya dengan intensitas cahaya. Larva ikan clown sudah mampu memangsa sebesar 5 individu rotifera pada intensitas cahaya cukup rendah 70 lux pada pagi hari, sedang puncak pemangsaan terjadi mulai pukul 13.00 hingga 16.00 dengan rata-rata pemangsaan 57 rotifera/larva, di mana intensitas cahaya mulai menurun dari maksimum 425 lux menjadi 256 lux.

Pada saat larva berumur 10 hari setelah menetas, tidak terlihat hubungan yang nyata antara intensitas cahaya pada pola pemangsaan, di mana pada saat intensitas cahaya cukup tinggi 515 lux pada pukul 10.00 pemangsaan rotifera tercatat hanya 55 rotifera/larva yang jauh lebih rendah dibanding pemangsaan pukul 16.00 yang mencapai 73 rotifera/larva pada intensitas cahaya yang hanya sebesar 181 lux (Gambar 2). Keragaan yang sama juga dicatat oleh Melianawati et al. 


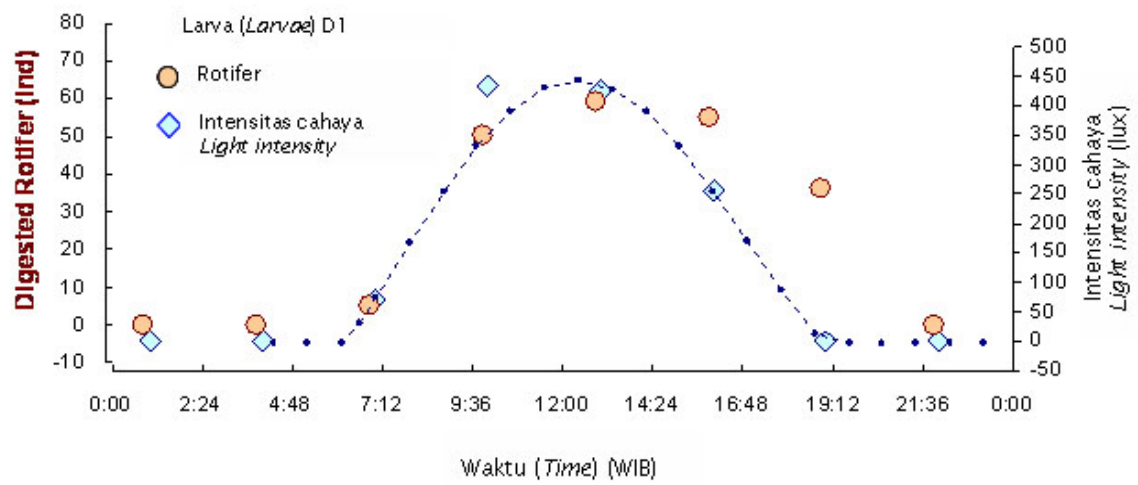

Gambar 1. Pola pemangsaan larva ikan clown umur sehari pada rotifer

Figure 1. Feeding pattern of one-day-old clown fish larva

(2006a) pada pemeliharaan larva kakap merah di mana puncak pemangsaan terjadi pada pukul 15.00 hingga pukul 17.00 dengan intensitas cahaya 200-300 lux. Demikian juga pada pemeliharaan larva kerapu sunu umur 10 hari dengan pemangsaan terbanyak terjadi mulai pukul 14.00 hingga 17.00 pada intensitas cahaya 500-1500 lux (Melianawati et al., 2006b).

Pola pemangsaan pada nauplii Artemia kemungkinan dipengaruhi oleh tersedianya intensitas cahaya, di mana larva umur 10 hari memilih memangsa nauplii Artemia sebesar 14\% pada intensitas cahaya 515 lux pada pukul 10.00 dibanding hanya $8 \%$ pada saat intensitas cahaya menurun menjadi 181 lux pada sore hari (16.00) (Gambar 3). Namun mungkin lebih pada sifat selektif memangsa sebab nauplii Artemia diberikan dua kali perhari pada pukul 10.00 dan pukul 15.30 wita dan pada saat itu intensitas cahaya sebesar 500 dan 200 lux. Kemampuan dan tabiat memangsa juga punya peranan pada pemilihan pakan, di mana dilaporkan larva umur tujuh hari sudah memiliki

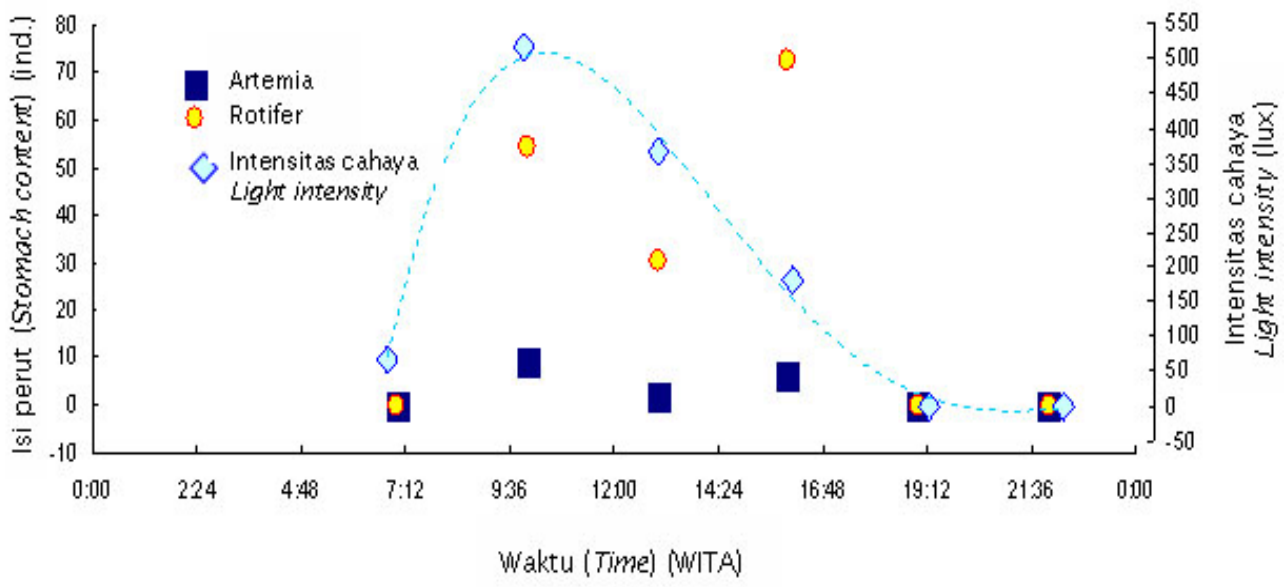

Gambar 2. Pola pemangsaan larva ikan clown umur sepuluh hari pada rotifera dan nauplii artemia Figure 2. Feeding pattern of ten-days-old clown fish larvae on rotifers and Artemia nauplii 


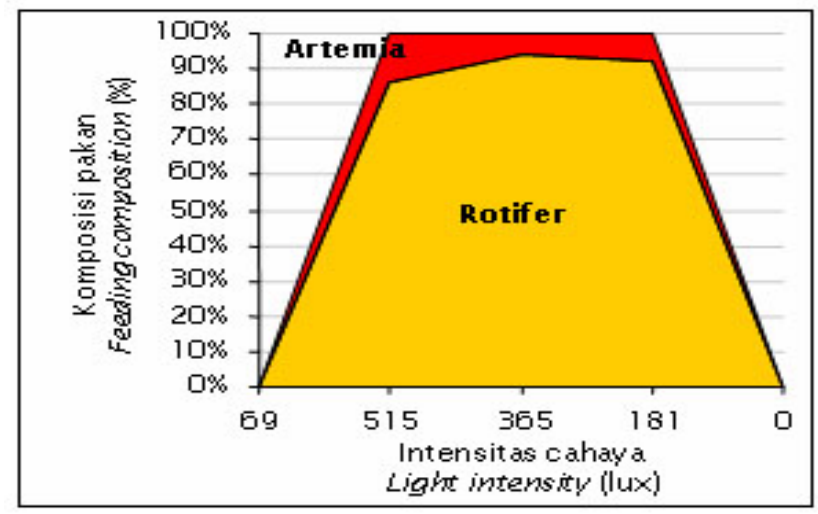

Gambar 3. Pola pemilihan pakan larva ikan clown umur 10 hari pada jasad pakan rotifera (kuning) dan nauplii Artemia (merah)

Figure 3. Feeding preference of D-10 clown fish larvae on rotifers (yellow) and nauplii Artemia (red)

gigi sehingga mampu memangsa jasad pakan yang lebih beragam. Di samping itu, kemungkinan terdapat pengaruh warna asli dari jasad pakan, di mana nauplii Artemia cenderung berwarna jingga kemerahan, sedang rotifera transparan dengan lapisan dinding tubuh berkilat yang memantulkan cahaya.

Komparasi data pemangsaan larva ikan clown umur sehari dan 10 hari, dengan data pemangsaan larva kakap merah maupun kerapu sunu (Melianawati et al., 2006a; 2006b) terdapat kesamaan pada alokasi waktu dan berbeda pada intensitas cahaya. Faktor yang berpengaruh pada pola pemangsaan larva ikan laut yang dipelihara dengan pakan utama rotifera diduga karena kualitas cahaya (warna), yang secara tidak langsung telah dibuktikan dengan berbagai penelitian nuansa warna wadah pemeliharaan larva bandeng Chanos chanos (Ahmad et al., 1994; Ahmad \& Aslianti, 1996) dan larva kerapu bebek Cromileptes altivelis (Aslianti et al., 1998) yang menunjukkan warna kuning menghasilkan sintasan lebih baik pada pemeliharaan awal larva. Gehrke (1994) juga menyatakan panjang gelombang yang lebih besar (yellow/orange wavebands) menghasilkan respon fototaktik terbaik dari larva golden perch, Macquana ambigua dan silver perch, Bidyanus bidyanus dalam penelitiannya tentang pengaruh intensitas cahaya dan panjang gelombang pada tingkah laku fototaktik larva.

Gambar 1 dan 2 nampak jelas pemangsaan optimal terjadi pada waktu posisi matahari mulai berada di bagian barat, dan seperti diketahui pada saat matahari terbenam akan dominan dengan spektrum warna merah (18.00), dan pada pukul 15.00-17.00 kemungkinan terbesar cahaya matahari terdispersi ke warna kuning-jingga karena adanya effek "kaca prisma" dari lapisan atmosfer. Keragaan seperti ini secara teoritis dapat dijelaskan sebagai berikut: lapisan atmosfer bumi yang mencapai 400 mil yang tersusun dari trofosfer $(0-10 \mathrm{mil})$ stratosfer (10-20 mil) chemosfer (20-50 mil) ionosfer (50-250 mil) serta mesosfer (250-400 mil) (Anonimous, 1955), dan pada sore hari sinar matahari akan menempuh lapisan atmosfer (b) lebih jauh dibanding pada tengah hari (a) di mana semua spektrum cahaya menembus masuk membentuk cahaya putih (Gambar 4). Di samping itu penguapan yang tinggi pada permukaan bumi sepanjang penyinaran matahari membentuk kumpulan uap air dan molekul udara yang padat di lapisan trofosfer dan stratosfer pada sore hari (18.00) yang akan menghambat spektrum cahaya gelombang pendek (ultraviolet) dan hanya spektrum cahaya gelombang panjang (infrared) yang dominan sampai permukaan bumi. 

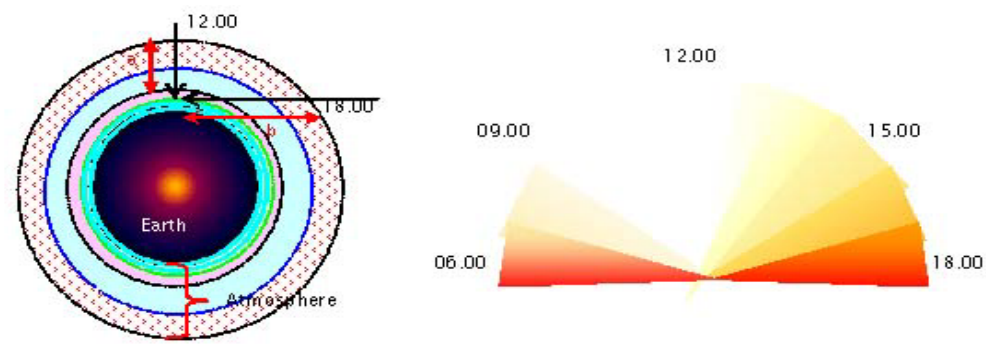

Gambar 4. Dugaan pola spektrum warna cahaya yang sampai ke permukaan bumi setiap hari

Figure 4. Assuming of daily color spectrum pattern of light penetrating to the surface of earth

Larva ikan clown yang baru menetas memiliki panjang total $4 \mathrm{~mm}$, pigmentasi mata yang telah sempurna (Setiawati et al., 2007) dengan lebar bukaan mulut dari arah dorsal sebesar $400 \mu$ pada umur D1, dan sudah bergerak aktif mencari mangsa. Hal ini disebabkan pada saat perkembangan embrionya kelengkapan morfologi organ pemangsaan seperti pigmentasi mata, mulut maupun sirip-sirip renang telah terbentuk sempurna (Wardoyo et al., 2006).

Pada umur yang kesepuluh (D-10) larva telah memiliki ukuran panjang total rata-rata sebesar 7,50 $\mathrm{mm}$ dan panjang standar 5,88 $\mathrm{mm}$, dengan persamaan regresi linier $\mathbf{y}=$ 0,8293x-0,3435 (Gambar 5) yang memberi

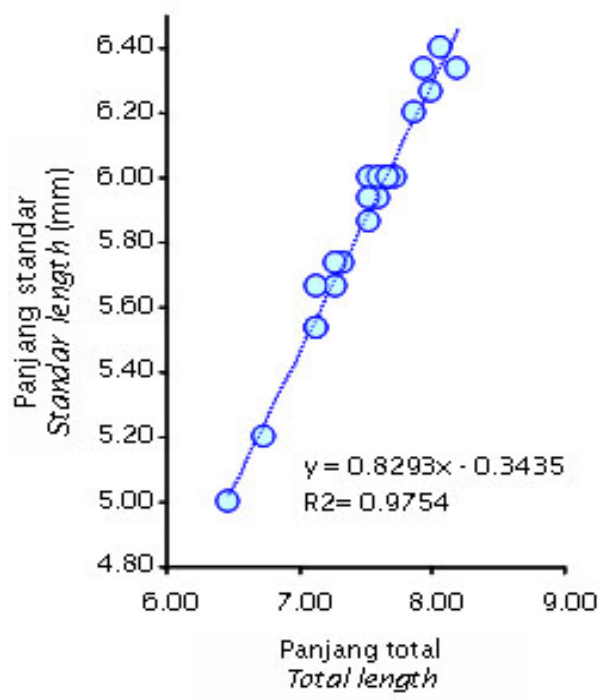

Gambar 5. Hubungan panjang total (TL) dengan panjang standar (SL) larva ikan clown umur 10 hari

Figure 5. Relationship between total length and the standard length of ten-daysold clown fish larva 
gambaran populasi larva yang dipelihara pada penelitian ini mempunyai perkembangan yang normal dan seragam ( $\mathbf{r}^{2}$ mendekati $\left.\mathbf{1}\right)$.

\section{KESIMPULAN DAN SARAN}

Ketersediaan cahaya sangat penting pada pemeliharaan larva ikan clown dalam hubungannya dengan kemampuan pemangsaan dari larva. Sedangkan besaran intensitas (quantity) cahaya bukan faktor yang menentukan pada pemangsaan maksimal larva, tetapi diduga spektrum/warna (quality) cahaya akan lebih berperanan pada suksesnya pemangsaan.

Hipotesis ini perlu dikaji lebih lanjut dengan melakukan penelitian yang lebih spesifik mengenai penyediaan dan manipulasi lingkungan pemeliharaan dengan beberapa warna/spektrum cahaya (artificial lighting) yang berbeda dan penggunaan sistem filter warna.

\section{UCAPAN TERIMA KASIH}

Penelitian ini dilakukan atas kerjasama di BBRPBL, Gondol dan CV Dinar, Denpasar dalam rangka realisasi kerja sama penelitian perbenihan dan produksi ikan hias laut. Ucapan terima kasih juga diberikan kepada Putu Widnyana, Savina (Staff CV Dinar), Feri Priatna, dan Made Buda.

\section{DAFTAR PUSTAKA}

Ahmad, T., T. Aslianti, dan D. Rohaniawan. 1994. Laju pertumbuhan dan kelangsungan hidup nener Chanos chanos dalam berbagai nuansa warna wadah. J. Pen. Budidaya Pantai. 10(1): 123-134.

Ahmad, T. dan T. Aslianti. 1996. Kelangsungan hidup dan pertumbuhan larva bandeng (Chanos chanos) dalam berbagai kroma nuansa jingga. Laporan Penelitian 19951996. 12 pp.

Allen, G. 2000. Marine Fishes of South-East Asia. Periplus Editions Ltd. Australian. 292 pp.

Anonim. 2006. Komunikasi pribadi dengan eksportir ikan hias di Denpasar.

Anonimous. 1955. The Canopy of Air in The World We Live In, LIFE and Lincoln Barnet. p. 6486.

Aslianti, T., Wardoyo, J.H. Hutapea, S. Ismi, dan K.M. Setiawati, 1998. Pemeliharaan larva kerapu bebek Cromileptes altivelis dalam wadah berbeda warna. J. Pen. Per. Pantai. IV(3): 25-31.

Gehrke, P.C. 1994. Influence of light intensity and wavelength on phototactic behaviour of larval silver perch Bidyanus bidyanus and golden perch Macquana ambigua and the effectiveness of lighttraps. J. Fish Biol. 44(5): $741-751$.

Imanto, P.T., R. Melianawati, dan T. Setiadharma. 2001. Pola pemangsaan larva kerapu lumpur (Epinephelus coioides). Dalam Sudradjat, A., Heruwati, E.S., Poernomo, A., Rukyiani, A., Widodo, J., dan Danakusumah, E. Teknologi Budidaya Laut dan Pengembangan Sea Farming di Indonesia. Puslitbang Eksplorasi Laut dan Perikanan. p. 175-182.

Kuiter, R.H. 1996. Guide to Sea Fisheries of Australia. A comprehensive reference for divers \& fishermen. New Holland Publisher (Australia). $433 \mathrm{pp}$.

Melianawati, R., P.T. Imanto, dan M. Suastika. 2006a. Pola Pemangsaan Larva Kakap Merah Lutjanus sebae. J. Riset Akuakultur.1(1): 49-54.

Melianawati, R.; R. Andamari, dan P.T. Imanto. 2006b. Aktivitas makan harian larva ikan kerapu sunu (Plectropomus leopardus). Dalam Murwantoko et al., 2006. Prosiding Seminar Nasional Tahunan III Hasil Penelitian Perikanan dan Kelautan 27 Juli 2006. p. 266-273.

Poernomo, A., S. Mardlijah, M.L. Linting, E.M. Amin, dan Widjopriono. 2003. Ikan hias laut Indonesia. Penebar Swadaya. 182 pp.

Setiawati, K.M., Wardoyo, dan D. Kusumawati. 2007. Pemeliharaan larva ikan clown (Amphiprion ocellaris) dengan manajemen pakan dan pengamatan aspek biologi ikan injel (Euxiphipops sp.). Laporan Hasil Riset T.A 2006. BBRPBL Gondol Bali. p. 142-157.

Wardoyo, K.M. Setiawati, D. Kusumawati, J.H. Hutapea, and Yunus. 2006. Perkembangan embrio ikan clown (Amphiprion ocellaris). Prosiding Konferensi Akuakultur Indonesia "Inovasi Teknologi Menuju Industri Akuakultur Global. Universitas Diponegoro, Semarang. p. 231-234.

Wilkerson, J.D. 2003. Clown fishes. A guide to their captive care, breeding \& natural history. Microcosm Ltd. Charlotte. 240 pp. 